\title{
A Pharmacist designed Protocol for the management of Acute Alcohol Withdrawal Syndrome (AAWS) in the Intensive Care Unit: A Pilot Study
}

\author{
Roaa Matouq Khinkar ${ }^{1 *}$, Ruchit Marfatia ${ }^{2}$ and Nicole Clark ${ }^{2}$ \\ ${ }^{1}$ Department of Clinical Pharmacy, College of Pharmacy, King Abdulaziz University, Jeddah, Saudi Arabia \\ ${ }^{2}$ Hallmark Health System, Medford, MA, USA
}

\section{Article Info}

\section{*Corresponding author:}

Roaa Matouq Khinkar

Department of Clinical Pharmacy

College of Pharmacy

King Abdulaziz University

Jeddah

Saudi Arabia

E-mail: rkhinkar@kau.edu.sa rmkhinkar@gmail.com

Received: September 29, 2017

Accepted: October 24, 2017

Published: October 30, 2017

Citation: Khinkar RM, Marfatia R, Clark N. A Pharmacist designed Protocol for the management of Acute Alcohol Withdrawal Syndrome (Aaws) in the Intensive Care Unit: A Pilot Study. Madridge J Clin Res. 2017; 1(1): 27-30.

doi: $10.18689 / \mathrm{mjcr}-1000105$

Copyright: (c) 2017 The Author(s). This work is licensed under a Creative Commons Attribution 4.0 International License, which permits unrestricted use, distribution, and reproduction in any medium, provided the original work is properly cited.

Published by Madridge Publishers

\begin{abstract}
Background: Many cases of acute alcohol withdrawal syndrome are refractory to benzodiazepines. The demand for an appropriate protocol to manage such cases is on the rise. Previous studies done on phenobarbital have shown its superiority to benzodiazepines in terms of managing acute alcohol withdrawal syndrome. By other means, phenobarbital decreases the use of benzodiazepines, need for intubation, and ICU length of stay (ICU LOS).

Objectives: This study was conducted to evaluate a new alcohol detoxification protocol i.e. using phenobarbital monotherapy as an alternative to benzodiazepines monotherapy.

Methods: Design: Prospective cohort study in which study group was compared to control group taken prior to intervention. Primary endpoints: number of ventilation free days. Secondary endpoints: total dose of benzodiazepines used, and ICU length of stay (ICU LOS). Inclusion criteria: Physicians utilized phenobarbital protocol when managing severe cases of alcohol detoxification resistant to benzodiazepines. Physicians evaluated if a patient is an appropriate candidate for phenobarbital protocol using protocol parameters and available patient data. Statistical analysis: a two-sample t-test was conducted on continuous data. Chi-square statistic was used for discrete variables.
\end{abstract}

Results: The primary end point was not statistically significant. The number of ventilation free days was 6 days for pre-intervention group and 8 days for post-intervention group $p=0.27$. The secondary endpoints were not statistically significant. The total dose of benzodiazepines used equivalent to lorazepam was $235 \mathrm{mg}$ for pre-intervention group and $41 \mathrm{mg}$ for post-intervention group $p=0.21$. The total ICU length of stay (ICU LOS) was 6 days for pre-intervention group and 3 days for post-intervention group; $p=0.05$.

Conclusion: This study did not find anything significant but descriptive data suggest that the phenobarbital protocol may provide a useful alternative to benzodiazepines. The findings of descriptive data resemble the outcomes of the previous studies done on phenobarbital for the management of acute alcohol withdrawal syndromes refractory to benzodiazepines. However future study is needed with larger sample size.

Keywords: Acute alcohol withdrawal syndrome (AAWS); Benzodiazepines, ICU length of stay (ICU LOS); Phenobarbital; Pharmacy; Ventilation free days.

Abbreviations: AAWS: Acute Alcohol Withdrawal Syndrome; AWS: Alcohol Withdrawal Syndrome; AUD: Alcohol Use Disorder; ICU: Intensive Care Unit; ICU LOS: ICU Length of Stay; ED: Emergency Department; DT: Delirium Tremens; MICU: Medical Intensive Care Unit; CIWA: Clinical Institute Withdrawal Assessment; PO: Oral; IM: Intramuscular; CC: Critical Care; ER: Emergency Room; MD: Medical Doctors; ICD-10: The 10th revision of the International Statistical Classification of Diseases and Related Health Problems; HHS: Hallmark Health System; PGY1: Post-Graduate Year 1. 


\section{Introduction}

Alcohol withdrawal syndrome (AWS) and alcohol use disorder (AUD) have been adding extra burdens to the already strained healthcare system. In the United States, around $7.2 \%$ or 17 million adults and more than 800,000 teens have AUD [1]. But when it comes to acute alcohol withdrawal syndrome (AAWS) or refractory cases of AWS, costs associated with labor, time, prolonged inpatient stays, and treatment become burdensome. Many drugs have been used for the management of AWS. None of them have shown its superiority over the other one. Examples of the drugs used are benzodiazepines, phenobarbital, carbamazepine, clonidine, propofol, and dexmedetomidine. In the current practice, benzodiazepines are the mainstay treatment for all cases of alcohol withdrawal [2]. And when it comes to refractory cases of AWS, benzodiazepines monotherapy has struggled to manage such cases. However, phenobarbital has showed some promise in this regard [3]. Even though there are not many studies done on phenobarbital for the management of AWS, phenobarbital seemed to succeed in managing cases of AWS refractory to benzodiazepines in those studies. Of the previous studies done on phenobarbital, a randomized, controlled, partially double-blind study done by Kaim and Keltt et al (1972) showed that phenobarbital is as effective as benzodiazepines for alcohol detoxification [4]. An uncontrolled study done by Young et al (1987) showed that phenobarbital is effective in the emergency department (ED) to treat seizure related to AWS [5]. Also, a retrospective chart review conducted by Lutzen et al (2008) concluded that phenobarbital is associated with low rate of respiratory depression [6]. On top of that, a double-blind study done by Kramp et al (1978) showed that phenobarbital is superior to benzodiazepines in terms of managing AAWS [7]. Per Kramp et al (1978) study, patients who presented to the hospital with delirium tremens (DT) were divided in 3 categories based on the presence of (DT1): tremor only, (DT2): tremor + hallucination, and (DT3): tremor + hallucination + disorientation. The effects of treatment were statistically significant in DT3; barbital was significantly superior to diazepam $(p<.05)$, although no significance was found for DT1 and DT2. And unlike benzodiazepines, retrospective studies done by Gold et al (2007) and Duby et al (2014) found that phenobarbital appears to decrease mechanical ventilation and ICU admission [8, 9]. Prior studies done for the management of AWS, phenobarbital was mostly used as an adjunctive to benzodiazepines and only few studies examined the use of phenobarbital monotherapy for AWS. The objective of this study is to evaluate a new alcohol detoxification protocol using phenobarbital monotherapy as an alternative to benzodiazepines monotherapy.

\section{Methods}

Setting: The design of this study was a prospective cohort study in which the study group was compared to historical control group taken prior to intervention. In other words, postintervention group (study group) was compared to preintervention group (control group). This study was conducted at one of the Hallmark Health System Hospitals, namely Melrose Wakefield Hospital located in Melrose, Massachusetts, USA.
Melrose Wakefield Hospital is a community based healthcare system with a total of 178 beds including 7 beds in the medical intensive care unit (MICU). The study period was 90 days for both groups. For pre-intervention group, it was challenging to collect data for 90 days in a row. Accordingly, ICD-10-alcohol withdrawal was used to capture subjects for this group, and 366 patients were identified throughout 2016. Since there was no data available for 90 days in a row for this group, patients with different periods of admissions were selected; but many patients included in this group were admitted during March 1st through May 31st, 2016. As phenobarbital protocol was implemented on March 1st 2017, data collection for postintervention group remained active for 90 days; until May 31st 2017. Inclusion and exclusion criteria: Physicians utilized phenobarbital protocol when managing severe cases of alcohol detoxification resistant to benzodiazepines. For pre-intervention group, any patient started on Clinical Institute Withdrawal Assessment (CIWA) protocol, required intubation, and ICU admission were included. All others who did not require at least either ICU admission or intubation were excluded. For postintervention group, patients should have one or more of the followings to be eligible for phenobarbital protocol; delirium tremens (DT), seizures, benzodiazepines abuse, previous ICU stays with intubation, or/and any patient as deemed appropriate by physicians in ER/ICU. Study outcomes: The primary outcome measure was mean ventilator free days. The secondary outcomes included mean benzodiazepines use, ICU length of stay (ICU LOS). Intervention: Physicians evaluated if a patient was an appropriate candidate for phenobarbital protocol using protocol parameters and available patient data. This protocol started the patients on loading dose(s) of phenobarbital on day 1. The loading dose of phenobarbital used was $15 \mathrm{mg} / \mathrm{kg}$ given as $10 \mathrm{mg} / \mathrm{kg}$ initially, and then $5 \mathrm{mg} / \mathrm{kg}$ was given as a rescue dose after an hour if patient did not respond to the initial dose. On days 2 through 7, patients were started on maintenance tapering doses of phenobarbital either PO or IM [10]. Clonidine, dexmedetomidine, hydroxyzine, and haloperidol were used as supportive therapy [11, 12, 13, 14]. Phenobarbital protocol eligibility parameters included one or more of the followings: delirium tremens (DT), seizures, previous ICU stays with intubation, benzodiazepines abuse, and/or any patients as deemed appropriate by medical doctors (MD) in ER/ICU.

Statistical analysis: A two-sample t-test was conducted on continuous data. Chi-square statistic was used for discrete variables. Resources: In-service was provided to educate medical staff on phenobarbital protocol including CC (critical care) and ER (emergency room) physicians, nurses, and pharmacists.

\section{Results}

Of 366 patients admitted from January 2016 to December 2016, only 41 patients were included in the pre-intervention group as they met the inclusion criteria. Many of the 41 patients were admitted from March 2016 to May 2016. For the postintervention group, only 8 patients were qualified to receive phenobarbital protocol for the period from March through May 2017. Baseline characteristics for both groups were included in 
Table 1. Of the 41 patients in the pre-intervention group, 8 patients required intubation due acute alcohol withdrawal syndrome, and average days of intubation were 3 days. Of the 8 patients in the post-intervention group, only 1 patient was intubated due to sepsis, and average days of intubation were 6 days. Accordingly, that patient who was intubated was excluded from study outcomes since intubation was related to sepsis and not alcohol withdrawal. The average ventilator free days were 6 days (pre-intervention group) vs. 8 days (post-intervention group), $p=0.27$ (Figure 1); which was not statistically significant, however it appears clinically significant since none of the patient in the post-intervention group required intubation for acute alcohol withdrawal syndromes. However, there is not enough sample size to deduce any concrete conclusion. The average dose of benzodiazepines used (converted to lorazepam equivalent) was $235 \mathrm{mg}$ (pre-intervention group) vs. $41 \mathrm{mg}$ (post-intervention group); $p=0.21$ (Figure 2), and the average ICU length of stay (ICU LOS) was 6 days (pre-intervention group) vs. 3 days (post-intervention group); $p=0.05$ (Figure 3 ).

Table 1. Baseline Characteristics

\begin{tabular}{|c|c|c|}
\hline Criteria & Pre-intervention Group & Post-intervention Group \\
\hline Number of patients & $N=41$ & $N=8$ \\
\hline \multicolumn{3}{|l|}{ Gender } \\
\hline Females & 10 & 1 \\
\hline Males & 31 & 7 \\
\hline Age & 48 Y.O. & 43 Y.O. \\
\hline Weight (Wt) & $79 \mathrm{Kg}$ & $78 \mathrm{Kg}$ \\
\hline Height $(\mathrm{Ht})$ & $171 \mathrm{~cm}$ & $177 \mathrm{~cm}$ \\
\hline Drug Abuse & $\begin{array}{l}20 \text { patients (Benzodiazepines, } \\
\text { Phenobarbital, } \\
\text { Amphetamines, Cocaine, } \\
\text { Oxycodone, Opiates, Heroin, } \\
\text { Marijuana, Tramadol) }\end{array}$ & $\begin{array}{l}2 \text { patients (Benzodiazepines, } \\
\text { Amphetamines) }\end{array}$ \\
\hline Drug Overdose & $\begin{array}{l}1 \text { (Paroxetine, } \\
\text { Acetaminophen) }\end{array}$ & None \\
\hline \multicolumn{3}{|l|}{ Labs } \\
\hline $\begin{array}{l}\text { Serum } \\
\text { Creatinine }(\mathrm{SCr})\end{array}$ & $1.3 \mathrm{mg} / \mathrm{dl}$ & $0.8 \mathrm{mg} / \mathrm{dl}$ \\
\hline Total bilirubin & 1.1 & 1.4 \\
\hline AST & 141 & 127 \\
\hline ALT & 73.5 & 64 \\
\hline AST/ALT & 2.1 & 2.1 \\
\hline Serum Alcohol & $114 \mathrm{mg} / \mathrm{dl}$ & $167 \mathrm{mg} / \mathrm{dl}$ \\
\hline Criteria & Pre-intervention Group & Post-intervention Group \\
\hline $\begin{array}{l}\text { Drinks } \\
\text { consumptions }\end{array}$ & $\begin{array}{l}\text { Heavy drinking (8 patients) } \\
5 \text { shots-1.5 L of vodka ( } 9 \\
\text { patients) } \\
2 \text { pints of rum/day ( } 1 \text { patient) } \\
2-12 \text { beers +/-whisky ( } 6 \\
\text { patients) } \\
\text { Alcohol abuse (17 patients) }\end{array}$ & $\begin{array}{l}\text { Heavy drinking ( } 1 \text { patient) } \\
1 / 2 \text { gallon of vodka ( } 1 \text { patient) } \\
1-20 \text { beers/day ( } 3 \text { patients) } \\
\text { Alcohol abuse ( } 2 \text { patients) } \\
\text { A couple of beer daily ( } 1 \\
\text { patient) }\end{array}$ \\
\hline $\begin{array}{l}\text { Signs and } \\
\text { symptoms due to } \\
\text { alcohol withdrawal }\end{array}$ & $\begin{array}{l}\text { Delirium Tremens (4 patients) } \\
\text { Seizure (11 patients) } \\
\text { Altered mental status (AMS) } \\
\text { (2 patients) } \\
\text { Agitation (1 patient) } \\
\text { Tremor/shaking +/- } \\
\text { hallucination or delirium (10 } \\
\text { patients) } \\
\text { Unresponsive (3 patients) } \\
\text { Elevated blood pressure (BP) } \\
+ \text { heart rate(HR) (6 patients) } \\
\text { Alcohol withdrawal syndrome } \\
\text { (AWS) (4 patients) }\end{array}$ & $\begin{array}{l}\text { Seizure (4 patients) } \\
\text { Delirium + Confusion (1 } \\
\text { patient) } \\
\text { Alcohol withdrawal syndrome } \\
\text { (AWS) (2 patients) } \\
\end{array}$ \\
\hline
\end{tabular}

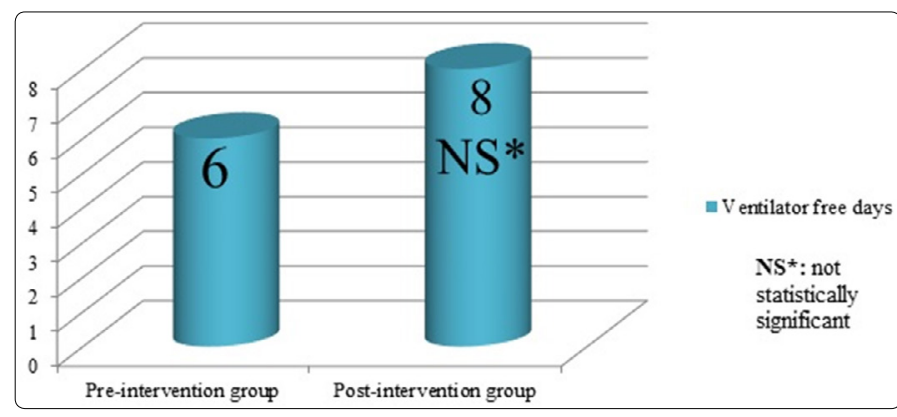

Figure 1. Ventilator free days.

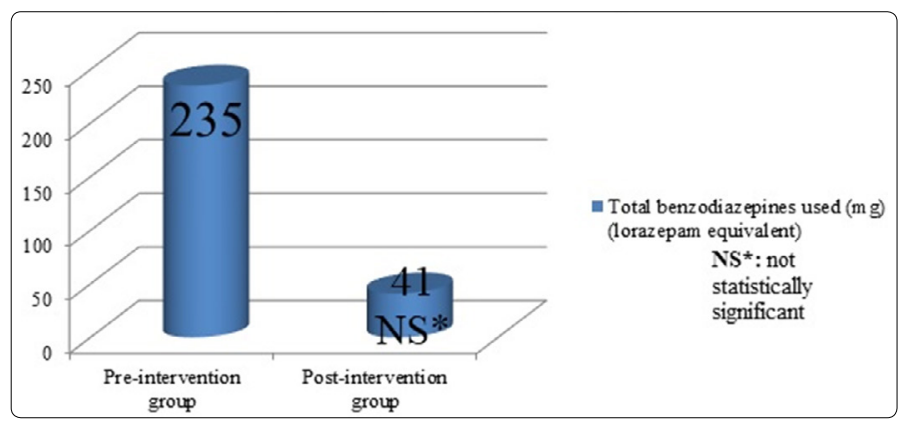

Figure 2. Total benzodiazepines used (lorazepam equivalent).

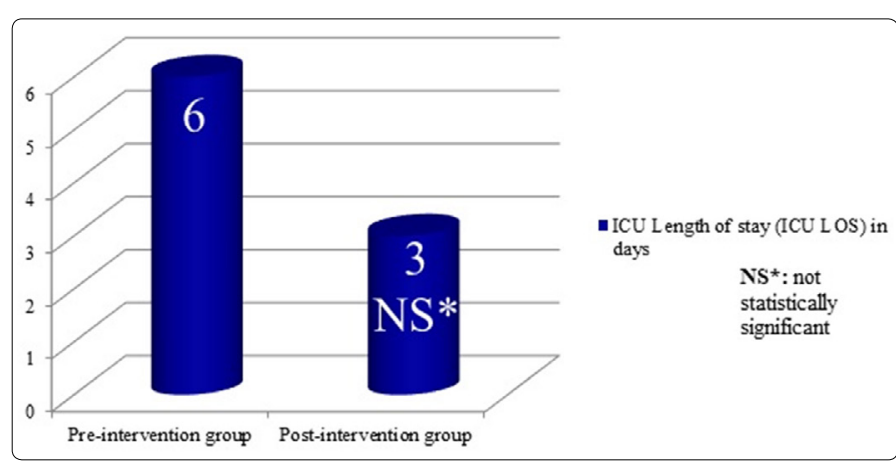

Figure 3. ICU Length of stay (ICU LOS).

\section{Discussion}

This study did not find any statistical significance between phenobarbital and benzodiazepines but descriptive data suggest that phenobarbital protocol might be a useful alternative to benzodiazepines for the management of acute alcohol withdrawal syndrome refractory to benzodiazepines. Apart from previous studies done on phenobarbital for acute alcohol withdrawal management, the descriptive data of this study show that phenobarbital might be a potential alternative to benzodiazepines for cases refractory to benzodiazepines. All patients who were eligible to be started on phenobarbital protocol were first started on CIWA protocol; however, their alcohol withdrawal syndromes were not controlled. The average dose of benzodiazepine used (equivalent to lorazepam) was 41 $\mathrm{mg}$. As patients were started on phenobarbital protocol, their symptoms of acute alcohol withdrawal were well-controlled and managed in a timely manner from Day 1 . Unlike the preintervention group where 8 patients required intubation with CIWA protocol for management of acute alcohol withdrawal syndrome, the post-intervention group patients, who were managed using phenobarbital protocol, did not require intubation and of the 8 patients, only 1 patient required intubation due to sepsis. An important fact to address here is 
that this patient was already intubated and was started on CIWA protocol before the initiation of phenobarbital protocol. Not only does phenobarbital appear to decrease the need for mechanical ventilation but also the use of benzodiazepines as well as ICU LOS. These findings match the conclusion of retrospective studies done by Gold et al (2007) and Duby et al (2014) $[8,9]$. In Gold et al study (2007), when high dose of phenobarbital was combined with diazepam, it showed significant reduction for need of mechanical ventilation as well as ICU LOS. In Duby et al study (2014), escalating the dose of phenobarbital was associated with significant decrease in ICU LOS, need for mechanical ventilation, benzodiazepines use, as well as need for continuous sedation. None of the 8 patients experienced any adverse effects related to phenobarbital. Another interesting finding to shed light on is that both groups received dexmedetomidine as a supportive therapy. However, the post-intervention group required less dexmedetomidine than the pre-intervention group.

In other words, the post-intervention group required less sedation than the pre-intervention group $(628.6 \mathrm{mcg}$ of dexmedetomidine vs. $2370.7 \mathrm{mcg}$ of dexmedetomidine, $p=0.31$ ) Table 2. This exactly matches the finding of a retrospective study done by Duby et al (2014) where the post-intervention group had significant reduction in the need for continuous sedation ( $24 \%$ vs $55 \%, p<.001)$ [9]. In addition to this, some patients in the pre-intervention group required propofol for further management of the acute alcohol withdrawal syndrome Table 2. As all other studies, this study has some strengths and limitations. This study was conducted in a community hospital, and it is the first community hospital in New England, USA that conducted such a study to the authors best of knowledge. Few limitations of this study were-first, we could not find data for 90 days in a row for the pre-intervention group (historical control group) and this resulted in selecting random patients with different timeframes throughout 2016.Secondly, there were not enough patients in the post-intervention group (study group). The power of the study was calculated for using the online calculator for statistical power [15]. Having said that further collection of data is required and the study should be continued for at least another year to get the target sample size, thus the statistical significance could be achieved.

Table 2. Supportive Therapy

\begin{tabular}{|l|l|l|}
\hline Criteria & $\begin{array}{l}\text { Pre-intervention } \\
\text { Group }\end{array}$ & $\begin{array}{l}\text { Post-intervention } \\
\text { Group }\end{array}$ \\
\hline Number of patients & $\mathrm{N}=41$ & $\mathrm{~N}=8$ \\
\hline Clonidine (Average) & $0.2 \mathrm{mg}$ & $0.5 \mathrm{mg}$ \\
\hline Haloperidol (Average) & $14.3 \mathrm{mg}$ & $15.3 \mathrm{mg}$ \\
\hline Hydroxyzine (Average) & None & None \\
\hline Dexmedetomidine (Average) & $2370.7 \mathrm{mcg}$ & $628.6 \mathrm{mcg}$ \\
\hline Propofol (Average) & $3004 \mathrm{mg}$ & None \\
\hline Trazodone (Average) & $3.7 \mathrm{mg}$ & None \\
\hline
\end{tabular}

Third limitation of the study was the short time period due to limited timeframe of PGY1 pharmacy residency program which is 12 months. Lastly, this study was done at one center only so patient population and characteristics were limited.

\section{Conclusion}

This study did not find anything significant but descriptive data suggest that the phenobarbital protocol may provide a useful alternative to benzodiazepines. The findings of descriptive data resemble the outcomes of the previous studies done on phenobarbital for the management of acute alcohol withdrawal syndromes refractory to benzodiazepines. However future study is needed with larger sample size.

\section{Acknowledgments}

Special thanks to my project mentor Dr. Ruchit Marfatia, and my clinical manager Dr. Nicole Clark for their guidance, support, and contributions to the success of my PGY1 residency project. Special thanks to the HHS pharmacy IT manager, Thomas Cerbone, for his great efforts and contributions to the success of the phenobarbital project. Many thanks to the HHS pharmacy, critical care and emergency room teams, and nursing department for their faith in the success of the phenobarbital project.

\section{References}

1. Makic MB. Alcohol Withdrawal Syndrome. Journal of PeriAnesthesia Nursing. 2017; 32(2): 140-141. doi: 10.1016/j.jopan.2017.01.007

2. DeCarolis DD, Rice $K L, H o ~ L$, Willenbring $M L$, Cassaro S. Symptom-driven lorazepam protocol for treatment of severe alcohol withdrawal delirium in the intensive care unit. Pharmacotherapy. 2007; 27(4): 510-518. doi: 10.1592/phco.27.4.510

3. Martin K, Katz A. The role of barbiturates for alcohol withdrawal syndrome. Psychosomatics. 2016; 57: 341-347. doi: 10.1016/j.psym.2016.02.011

4. Kaim SC, Klett CJ. Treatment of delirium tremens. A comparative evaluation of four drugs. QJ Stud Alcohol. 1972; 33: 1065-1072.

5. Young GP, Rores C, Murphy C, Dailey RH. Intravenous phenobarbital for alcohol withdrawal and convulsions. Ann EmergMed. 1987; 16: 847-850. doi: 10.1016/S0196-0644(87)80520-6

6. Lutzen L, Poulsen LM, Ulrichsen J. Respiratory depression in delirium tremens patients treated with phenobarbital. A retrospective study. Ugeskr Laeger. 2008; 170: 2018-2022.

7. Kramp P, Rafaelson OJ. Delirium tremens: a double-blind comparison of diazepam and barbital treatment. Acta PsychiatrScand. 1978; 58: 174-190. doi:10.1111/j.1600-0447.1978.tb06930.x

8. Gold JA, Rimal B, Nolan A, Nelson LS. A strategy of escalating doses of benzodiazepines and phenobarbital administration reduces the need for mechanical ventilation in delirium tremens. Crit Care Med. 2007; 35(3): 724-730. doi: 10.1097/01.CCM.0000256841.28351.80

9. Duby J, Berry A, Ghayyem P, Wilson MD, Cocanour CS. Alcohol withdrawal syndrome in critically ill patients: protocolized versus nonprotocolized management. Journal of Trauma and Acute Care Surgery. 2014; 77(6): 938-943. doi: 10.1097/TA.0000000000000352

10. Ives TJ, Mooney AJ, Gwyther RE. Pharmacokinetic dosing of phenobarbital in the treatment of alcohol withdrawal syndrome. South Med J. 1991; 84: 18-21.

11. Linn DD, Loeser KC. Dexmedetomidine for alcohol withdrawal syndrome. Annals of Pharmacotherapy. 2015; 49(12): 1336-1342. doi: 10.1177/1060028015607038

12. Mueller SW, Preslaski $\mathrm{CR}$, Kiser $\mathrm{TH}$, et al. A randomized, double-blind, placebo-controlled dose range study of dexmedetomidine as adjunctive therapy for alcohol withdrawal. Crit Care Med. 2014; 42(5): 1131-9. doi: 10.1097/CCM.0000000000000141

13. Braz LG, Navarro CLH, Braz JR, et al. Clonidine as adjuvant therapy for alcohol withdrawal syndrome in intensive care unit. Case Report. RevistaBrasileira de Anestesiologia. 2003; 53(6): 802-807. doi: 10.1590/ S0034-70942003000600011

14. Muzyk AJ, Fowler JA, Norwood DK, Chilipko A. Role of $\alpha 2$-agonists in the treatment of acute alcohol withdrawal. The Annals of Pharmacotherapy. 2011; 45: 649-57. doi: 10.1345/aph.1P575

15. Researcher's Toolkit. Statistical Power Calculators. DSS RESEARCH. 2017. 